\title{
Mollusc species richness and abundance from shelf to abyssal depths in the Ross Sea (Antarctica): the importance of fine-mesh towed gears and implications for future sampling
}

Claudio Ghiglione ${ }^{1,2} \cdot$ Maria Chiara Alvaro ${ }^{2,3} \cdot$ Paola Piazza $^{1,2} \cdot$ David Bowden $^{4} \cdot$ Huw J. Griffiths ${ }^{5}$ Cinzia Carota ${ }^{6}$ Consuelo R. Nava ${ }^{6}$ Stefano Schiaparelli2,3

${ }^{1}$ Department of Physical, Earth and Environmental Sciences, University of Siena, Siena, Italy

${ }^{2}$ Italian National Antarctic Museum (MNA), University of Genoa, Genoa, Italy

${ }^{3}$ Department of Earth, Environmental and Life Sciences (DISTAV), University of Genoa, Genoa, Italy

${ }^{4}$ National Institute of Water and Atmospheric Research (NIWA), Wellington, New Zealand

${ }^{5}$ British Antarctic Survey (BAS), Cambridge, United Kingdom

${ }^{6}$ Department of Economics and Statistics "Cognetti de Martiis", University of Turin, Turin, Italy

\section{Abstract}

In 2008, a large sampling campaign took place in the Ross Sea between $\sim 66^{\circ} \mathrm{S}$ and $\sim 77^{\circ} \mathrm{S}$ during the NIWA IPY-CAML voyage of R/V Tangaroa, as part of the Census of Antarctic Marine Life (CAML). Samples of benthos were obtained by using a variety of sampling methods from 64 stations at depths of between $283 \mathrm{~m}$ to $3490 \mathrm{~m}$. Mollusca accounted for 173 living species and 1034 specimens, which were analysed in terms of variation in richness and composition with latitude and depth, and to assess which macrofaunal size fraction contained the highest biodiversity. Differences were detected in species composition with latitude (averaged across depth groups) but not for depth (averaged across latitudinal groups). Richness varied locally and showed a variety of patterns according to the areas and depths considered. New species accounted for $\sim 7 \%$ of the total number of species and new regional records for $\sim 12 \%$. Rarity was high, with a $\sim 41 \%$ of species represented by single individuals and $~ 63 \%$ occurring at one station only. The greatest diversity was found in the fine fraction (i.e. $<4.1 \mathrm{~mm}$ ) suggesting that the systematic use of finemesh trawling in future sampling activities can be of help in accelerating the census of Antarctic mollusc fauna.

\section{Keywords}

Antarctica, Ross Sea, Victoria Land Coast, Seamounts, Benthos, Mollusca, Species Richness, Abundance, Fine-mesh, Sampling efficiency, Full census 
Introduction

The Ross Sea continental shelf, with an area of roughly $473 \mathrm{~km}^{2}$, is the second largest in Antarctica after the Weddell Sea. The average depth of the shelf is $500 \mathrm{~m}$, and the shelf break occurs at about $800-1000 \mathrm{~m}$, from where the continental slope extends steeply down to $3000 \mathrm{~m}$ (Clarke et al, 2007; Scambos et al. 2007). Beyond the continental slope to the north, there are a number of seamounts and islands, including the Scott Seamount chain, the Admiralty Seamount, and the Balleny Islands.

To date, around 28 historical and recent expeditions have collected benthic material in the region (Clarke et al, 2007; Griffiths et al. 2011; Schiaparelli et al. 2014 for the list of historical expeditions) making the Ross Sea continental shelf one of the best-studied Antarctic seabed areas (Clarke et al. 2007; Griffiths et al. 2011).

However, despite this significant historical sampling effort, our knowledge of the benthic diversity of the Ross Sea is still incomplete, as demonstrated by recent additions of both small (Rehm et al. 2007; Ghiglione et al. 2013; Lörz et al. 2013; Schiaparelli et al. 2014; BłażewiczPaszkowycz et al. 2014; Piazza et al. 2014) and large taxa, including the 3 metres tall hydroid Branchiocerianthus sp. (Schiaparelli et al. in prep.), the stalked crinoids communities found on the Admiralty seamount (Bowden et al. 2011; Eléaume et al. 2011) and the large bivalve of the genus Acesta found on the Scott Seamount (Piazza et al. 2015). During the International Polar Year (IPY, 2007/2008), under the coordination of Census of Antarctic Marine Life (CAML) (Schiaparelli et al. 2013), substantial new sampling campaigns were undertaken in several Antarctic areas including the Ross Sea, which was the focus of a research voyage, the IPY-CAML voyage (TAN0802) of the R/V Tangaroa.

In this paper we focus on Mollusca (all classes but Caudofoveata and Cephalopoda which were not present in the samples) one of the most extensively studied Phyla in Antarctica (Clarke and Johnston 2003; Griffiths et al. 2003), collected during the TAN0802. As with the earlier BioRoss voyage of the R/V Tangaroa in 2004 (Mitchell and Clark 2004; Schiaparelli et al. 2006), during the TAN0802 several benthic gears were deployed at each survey site in order to document the diversity of benthos. Deployment of multiple sampling gears with different mesh sizes at the same location is a well-known method in biodiversity assessment to compensate for the different catchability of the species (Bouchet et al. 2002; Longino et al. 2002; Clark et al. 2016).

The gear types used during the TAN0802 voyage, included a rough-bottom trawl, beam trawl, epibenthic sledge, and a fine-mesh epibenthic or "Brenke" sledge. The Brenke sled (Brandt et al. 2004; Brenke 2005; Lörz et al. 2013) is specifically designed to collect organisms from the benthic 
boundary layer and has previously been utilized in the Weddell Sea and the Atlantic sector of the Southern Ocean, especially at abyssal depths (Schwabe et al. 2007; Brandt et al. 2014; Jörger et al. 2014). The deployment of a Brenke sled during the TAN0802 expedition was its first use in the Ross Sea (Lörz et al. 2013). It also represents the second fine-mesh sampling event in the area, after the deployment in 2004 of a Rauschert dredge, which provided an unexpectedly large number of new records and species of molluscs for the Ross Sea (Ghiglione et al. 2013; Schiaparelli et al. 2014). The use of a Brenke sled during TAN0802 thus gave an opportunity to assess the distribution of mollusc biodiversity across size classes in Antarctica.

Answering to this question is becoming an important issue for research in Antarctica, which also goes outside the geographical scope of the study, here limited to Ross Sea. In fact, by considering the need of robust baseline data to measure future changes, it will be of key importance to know if specific sampling gears having a small mesh size (i.e. $500 \mu \mathrm{m}$ ) have to be routinely deployed in future sampling activities in order to retain the smaller fraction, i.e. the one showing the highest diversity.

In the deep sea, the observation that faunal diversity may be higher in smaller body-size fractions of the macrofauna has been clear since the 1960s, when mesh sizes smaller than $1 \mathrm{~mm}$ began to be routinely used, revolutionizing our knowledge of deep-sea diversity (Hessler and Sanders 1967). For molluscs in general, several studies highlighted that this could be a common pattern with peaks in numbers of individuals and species having been found for body size between 0.5 and $4 \mathrm{~mm}$ in deep-sea gastropods in the western North Atlantic (McClain 2004), between 1.9 and $4.1 \mathrm{~mm}$ in New Caledonian reef assemblages (Bouchet et al. 2002) and in the $<5 \mathrm{~mm}$ fraction in Vanuatu reef assemblages (Albano et al. 2011). However, exceptions are also known (see McClain 2004 and references therein).

An apparent lack of 'microfauna' in the Antarctic benthos was highlighted by Dell (1990: 264), who noted that this was likely to be a consequence of sorting methods that did not retain the smallest fraction of the fauna. However, fine-mesh trawling performed in 2004 with a Rauschert dredge (Schiaparelli et al. 2014) provided the first evidence that the smallest mollusc fraction in the Ross Sea is rich both in terms of species and specimens. If present data will confirmed this fact, it is clear that new ecological questions will probably have to be asked about the evolutionary, biogeographic and ecological mechanisms that may have led to a general 'miniaturization' of Antarctic mollusc fauna. The present data from TAN0802 provide a more extensive dataset with which to assess the diversity of Southern Ocean Mollusca in relation to body size. 
Study area and sample processing

107

The study area of TAN0802 covered a latitudinal range from $\sim 66^{\circ} \mathrm{S}$ to $\sim 77^{\circ} \mathrm{S}$, spanning the whole Ross Sea region from the Ross Ice Shelf up to the northern seamounts systems (Admiralty and Scott) (Fig. 1). Three broad areas were considered, namely the "Northern area" (from $66^{\circ} \mathrm{S}$ to $\sim 70^{\circ} \mathrm{S}$ ), the "Central area" (from $\sim 70^{\circ} \mathrm{S}$ to $\sim 74^{\circ} \mathrm{S}$ ) and the "Southern area" (from $\sim 74^{\circ} \mathrm{S}$ to $\sim 77^{\circ} \mathrm{S}$ ) (Hanchet et al. 2008), following a natural latitudinal gradient.

Benthic communities were sampled at sixty-four sampling events at depths ranging from 283 $\mathrm{m}$ to 3490 m (Fig. 1; Supplementary Table 1) by deploying four types of towed gears with different mesh-sizes: Rough-bottom trawl (ORH); Beam trawl (TB); Brenke sled (SEH) (note that this acronym is reported as such in agreement with the original report of Hanchet et al. 2008 but it is often reported as EBS in literature), and Epibenthic sled (SEL) (Hanchet et al. 2008). Rough-bottom trawl is a commercial-style fish trawl with $300 \mathrm{~mm}$ mesh in the forepart of the net, tapering through $100 \mathrm{~mm}$ and $60 \mathrm{~mm}$ mesh sections to a $40 \mathrm{~mm}$ mesh cod-end. The Beam trawl is a $4 \mathrm{~m}$ wide bottom trawl designed to sample mega-faunal benthic invertebrates and small benthic fish, having a $25 \mathrm{~mm}$ mesh size for the whole net length. The Brenke sled has two fine-mesh with 500 $\mu \mathrm{m}$ nets with rigid cod-end containers arranged one above the other (Brenke 2005, here, we report results from the upper and bottom net combined). The Epibenthic sled is a small sled with 1 $\mathrm{m}$ wide mouth developed for sampling mega-epifauna on rough terrain; it has a short net of 25 $\mathrm{mm}$ mesh inside a chafing cover of $100 \mathrm{~mm}$ mesh (Clarke and Stewart 2016). All gears were towed at approximately 1 knot, except for the ORH at 3 knots.

Macroinvertebrates were sorted on board, preserved in $90 \%$ ethanol (or, in some cases, kept at $-25^{\circ} \mathrm{C}$ for later DNA extraction). Fine fractions from Brenke sled catches were separated from the sediment through elutriation and preserved as bulk in $90 \%$ ethanol.

\section{$\underline{\text { Species classification }}$}

In the laboratory, living specimens were sorted under a stereomicroscope, divided into morphospecies and classified to the lowest possible taxonomical level. Minute species, whenever necessary, were photographed using an Environmental Scanning Electron Microscopy (ESEM, model Leo Stereoscan 440). In this contribution all the living fractions of Gastropoda, Bivalvia, 
Monoplacophora, Scaphopoda, Polyplacophora and Solenogatres were considered. Cephalopoda and Caudofoveata were not present in the samples.

Nomenclature of species was crosschecked and matched with WoRMS 140 (http://www.marinespecies.org; last check made on May 10, 2016). When available, molecular 141 data (COI barcodes obtained in the framework of the Italian "BAMBi" project, Barcoding of ANTABIF (the Antarctic node of the Global Biodiversity Information System; http://www.biodiversity.aq) in the collection of distributional data provided by the Italian National Antarctic Museum (MNA, Section of Genoa) (http://www.gbif.org/dataset/search?q=mna)

$\underline{\text { Statistical analyses }}$ (Ghiglione et al. in prep.).

Antarctic Marine Biodiversity, PNRA 2010/A1.10) were used in some cases used to split morphospecies lacking sound morphological characters (e.g. for the family Velutinidae). Specimens not classified to the specific level were included in the multivariate analyses and reported at the level of genus or family.

The resulting dataset of geographic occurrences of the species will be made available through

\section{$\underline{\text { Statistical analyses }}$}

Statistical analyses were performed to evaluate the effects of latitude and depth on species richness and composition and to compare species richness across body-size fractions.

Since the deployment of sampling gears was not even (e.g. SEL was only used on the rough bottoms of the seamounts) and the majority of specimens were collected by the Brenke sled (Supplementary Fig. 1 and 2), statistical analyses were performed separately on datasets from the different gears. In the specific, species richness was studied only on Brenke sled data while composition was studied on presence/absence data considering all gears.

Rarity was evaluated in terms of number of species collected as singletons (i.e. species found with a single specimen) and doubletons (i.e species found with two specimens only), or uniques (i.e. species occurring at a single station only) and duplicates (i.e. species occurring at two stations only).

\section{Effects of latitude and depth on species richness}

To understand richness patterns in relation to depth and latitude, Brenke sled samples were analysed through a combined analysis of rarefaction and extrapolation techniques. This analysis is 
based on diversity accumulation curves produced on empirical estimates of the principal Hill numbers (Chao et al. 2012, 2014). Individual-based (for geographic areas) and sample-based (for depth) interpolation (rarefaction) and extrapolation curves (Colwell et al. 2012) were computed using the online iNEXT package (Chao et al. 2016; https://chao.shinyapps.io/iNEXTOnline/), which allows the comparison of samples taking into account sample coverage and completeness (Chao and Jost 2012, Chao et al. 2014) in the R-statistical environment (http://www.r-project.org). Uncertainty of estimations was reported in terms of $95 \%$ confidence intervals under the multinomial model for the observed species sample frequencies (in the case of the individualbased interpolation/extrapolation curves) or under the Bernoulli product model for the incidence matrix (in the case of the sample-based interpolation/extrapolation curves) (Colwell et al. 2012). The non-overlap of $95 \%$ confidence interval was used as an indicator of statistical difference (Colwell et al. 2012).

\section{Effects of latitude and depth on species composition}

Species composition was evaluated through multivariate techniques to test the possible effects of latitude and depth in the structure of benthic communities using presence/absence data from all gears combined. In these analyses the factors "depth" (with levels: 1=0-500 m, 2=501-1000 m, $3 \geq 1001 \mathrm{~m}$ ) and "latitude" (with levels: Northern area, Central area and Southern area, in accord with Schiaparelli et al. 2006) were used. Bray-Curtis similarity index was then calculated and nonmetric multidimensional scaling (nmMDS) performed. Two-ways ANOSIM (Clarke 1993) was used to test the differences among the factors latitude and depth and decouple the covariation of depth and latitude. All multivariate analyses were performed with the software PRIMER 6 of Plymouth Marine Laboratory (Clarke and Gorley 2005).

\section{Comparison of species richness across body-size fractions}

The numbers of species shared among gears were visualized through Venn diagrams, prepared by using jvenny (Bardou et al. 2014) and multivariate analyses on the factor "gear" (with levels: $\mathrm{ORH}, \mathrm{TB}, \mathrm{SEH}$ and SEL) were performed on presence/absence data to statistically explore possible different sampling performances of the deployed gears.

Extrapolation and rarefaction analyses with iNEXT were also performed to highlight the completeness of the sampling (i.e. observed numbers of species compared to expected ones) on 
incidence data (i.e. presence/absence data). Finally, in order to compare the size-spectrum of species collected by each sampling gear, we counted the number of species present in different size-class bins having equivalent intervals (in a logarithm transformation with base 2, following Bouchet et al. 2002). The range size of the mollusc species considered was taken from the literature (when available) or directly measured on the collected specimens in the case of new species.

\section{Results}

From the 64 samples a total of 1034 living mollusc specimens belonging to 173 different species were collected. The full data set consisted of 509 specimens of Gastropoda (98 species), 446 specimens of Bivalvia (62 species), 29 specimens of Scaphopoda (8 species), 31 specimens of Polyplacophora (2 species), 8 specimens of Monoplacophora (2 species) and 11 specimens of Solenogastres (not divided into morphospecies and treated at the class level). The complete list of species and their occurrence in the different areas is reported in the supplementary Table 2.

Rarity

Out of the 173 species found, 71 were singletons, corresponding to $41.04 \%$ of the total number of species, and 34 species were doubletons (representing the $19.65 \%$ of the total). In terms of presence/absence data (i.e. incidence), 109 species were uniques (63.01\% of the total), and 39 species were duplicates (22.54\% of the total). Overall, $~ 54 \%$ of species were already reported in the literature for the Ross Sea, $\sim 12 \%$ represent new records (marked with '*' in the supplementary Table 2), $7 \%$ new species (marked with ${ }^{(* * \prime}$ in the supplementary Table 2 ), and $\sim 28 \%$ have uncertain status. This latter group is composed of new species or new records that are not easily classifiable at present due to the unavailability of detailed iconography for some species and the general need of direct comparisons with type materials, which is beyond the scope of the present contribution. The Brenke sled samples contained the highest numbers of new records and new species (Table 1).

\section{Effects of latitude and depth on species richness}


No differences in richness patterns were highlighted for Brenke data from the considered bathymetric ranges of 0-500 m, 501-1000 m and >1000 m (Supplementary Fig. 3) on incidence data. However, because latitude and depth are partially confounded, this analysis has to be treated with caution. In fact, if this analysis is done on abundance data for homogeneous groups of areas and depths, a variety of situations can be highlighted, indicating a high degree of heterogeneity (Fig. 2). Abyssal areas, for example, can be indistinguishable in numbers of expected species at depth $>3000 \mathrm{~m}$ in the northern area (Fig. 2a) but can remarkably differ in the central area in stations at almost identical depths (e.g. station 147 at $1610 \mathrm{~m}$ vs station 135 at $1645 \mathrm{~m}$, Fig. 2c). The same occurs in shelf stations (Fig. 2e) and in shelf to slope stations (Fig. 2d) but only at very low numbers of individuals (i.e. $<20$ individuals), while at higher numbers of individuals the

Effects of latitude and depth on species composition

At the significance threshold of 0.05 , composition varied (presence/absence data, all gears combined), among latitudinal areas across depth groups (2-ways ANOSIM global $\mathrm{R}=0.111$; $p=0.001$ ), with the Northern Area being statistically distinct from the Central and Southern ones (Fig. 3; Table 2). The same test performed for depths groups across latitudinal areas did not show

\section{Comparison of species richness and completeness across body-size fractions}

Due to the intrinsic sampling properties of each sampling gear, few species were common between sampling gears (Fig. 4). Accordingly, the multivariate analysis performed considering the factor gear (all gears combined, presence/absence data) showed that all gears differ in terms of collected species (ANOSIM global $R=0.17 ; p=0.001$ ) (Table 4). Only the rough-bottom trawl and the Beam trawl showed a higher similarity with 8 species in common (i.e. eight: Dentalium majorinum, Doris sp., Falsimargarita gemma, Marseniopsis mollis, Marseniopsis sp., Philobrya sublaevis, Prodoris clavigera and Tritoniella sp.) with an $\mathrm{R}$ value of 0.088 (Tab. 4). The highest number of shared species is between the Brenke sled and the Beam trawl (i.e. ten: Adacnarca nitens, Dentalium majorinum, Limatula simillima, Lissarca notorcadensis, Philobrya sublaevis, Propeamussium meridionale, Silicula rouchi, Thracia meridionalis, Tindaria antarctica, Yoldiella sabrina) despite the latter having a mesh 50 times larger than the former. Here, however, the 
multivariate analysis indicates large differences between the two sampling gears $(R=0.222$; $p=0.001)$ due to the higher number of species collected by the Brenke.

The largest fraction of species was found in the body-size range 0.9-4.1 $\mathrm{mm}$ that was present only in the Brenke sled samples (Fig. 5). The Brenke sled samples also provided the broadest spectrum of size classes (from 0.4 to $88 \mathrm{~mm}$ ), including some larger species that were retained by other gears with larger meshes (e.g. the Beam trawl) resulting in high cumulative richness (Fig. 6a) and sample completeness (Fig. 6b) curves.

\section{Discussion}

In biodiversity studies the achievement of an exhaustive list of species, i.e. a full census, for a given area is an ambitious task. Generally this process is also very expensive both in terms of time and costs. For these reasons, cost-effective compromises that might combine maximum sampling efficiency with a minimal sampling effort are usually desirable, as long as they guarantee meaningful statistical analyses.

In this context, several alternatives to a full census have been developed to speed the inventory process. Rapid assessment techniques, for example, have been designed to rapidly evaluate the biodiversity of critically important field sites around the world (more details at: http://www.conservation.org/projects/Pages/Rapid-Assessment-Program.aspx). These surveys, however, are principally meant for conservation purposes and used in prioritisation activities, rather than to exhaustively inventory all species present in an area.

When sampling activities are accomplished, a possible shortcut to speed the 'processing time' of collected species is the use of higher-taxon data as a surrogate for species richness (Gaston and Williams 1993). This choice of course greatly reduces the time required for sorting into Operational Taxonomic Units (OTUs) by adopting a coarser division. This method, however, needs to be initially tested for the group being studied and it usually works for genus-level data only (e.g. Souza et al. 2016), generally failing to give meaningful results at higher taxonomic levels.

However, when the target of the study is the real number of species and not a proxy for it, no similar shortcuts are possible and techniques maximizing the opportunity to record the highest possible number of species in time available for sampling have to be found.

To this aim, a well-known and effective approach that enables the collection of the number of species potentially close to the real one is the simultaneous use, in the same study area, of different sampling techniques. In this way, the different gears' designs partially compensate for 
differences in species catchability, maximising sampling efficiency (Bouchet et al. 2002; Longino et al. 2002). The statistical drawback of this method is that species abundances cannot be used, as these come from different sampling methods, each one with its own sampling bias, for example towards a given size range.

In Antarctica, an area of our planet where climate change impacts are expected to increase by 2100 (IPCC 2013, Bracegirdle et al. 2013) potentially leading to detrimental effects on the native fauna, the gathering of biodiversity data is of key importance. The assessment of a reference baseline for the diversity of the Antarctic marine fauna was one of the top five primary targets of the Census of Antarctic Marine Life (CAML) (Schiaparelli et al. 2013) and similar research priorities have also been highlighted by the recently accomplished SCAR horizon scan (Kennicutt et al. 2015) where a special focus was placed on the relationships between biodiversity and ecological processes.

The data reported here from the extensive sampling of the NIWA TAN0802 IPY-CAML voyage provide a benchmark from which to measure future changes in the Ross Sea and also provide a key test to evaluate our knowledge gaps and more specific gear-related sampling issues.

The results of our study demonstrate statistical differences in species composition between the Northern Area and the Central and Southern ones, but no variation related to depth across latitudinal areas. If only richness data are taken into account, by considering Brenke sled samples, a variety of patterns according to area and depth can be appreciated, denoting an overall large variability between samples even from purportedly similar areas.

As a whole, these results suggest the existence of complex patterns and non-linear correlations between environmental determinants and the composition of benthic communities in the Ross Sea. This is in substantial agreement with Cummings et al. (2010), where all available literature for the Ross Sea was reviewed in search for a common pattern determined by latitude, depth, or any other important explanatory variable. However, Cummings et al. (2010) found no clear trends, the outcomes of the studies varying by group considered, location and gear used. It is probable that macrobenthic assemblages in the Ross Sea are strongly influenced by a 'seafloor-habitat' control effect, defined by depth, slope, current speed immediately above the seabed and organic content of seafloor sediments as already suggested by Barry et al. (2003).

Besides the results focused on latitudinal or depth trends, the NIWA TAN0802 IPY-CAML data also allow for the evaluation of sampling performances of different gears and their relative contribution to a biodiversity studies when performed at a large geographical scale. In particular, among the considered gears, the catches of the fine-mesh sampling gear (i.e. Brenke sled) allowed 
for testing if the micromolluscs represented the larger proportion of the total molluscan fauna both in terms of richness and abundance. In accordance with what was found from fine-mesh samples obtained by a Rauschert dredge during the Latitudinal Gradient Program (R/V Italica 2004) expedition (Ghiglione et al. 2013; Schiaparelli et al. 2014), the Brenke sled provided the highest number of species and specimens compared to the other standard sampling gears (Supplementary Figure 2) and, in turn, of new species and new records for the area (Table 1; Supplementary Table 2 symbols “*” and “**” respectively).

Previously, the Brenke sled was used in several localities out of the Antarctic area (Brandt et al. 1995; Linse and Brandt 1998; Linse 2004; Kaiser et al. 2008; Kaiser et al. 2009; Brandt et al. 2013; Brandt et al. 2015) while, inside the Polar Front, it was deployed in the Weddell Sea and periantarctic areas only, especially in the abysses (Schwabe et al. 2007; Brandt et al. 2014; Jörger et al. 2014). In a few cases the benthic organisms collected with this gear were compared with the other gears, e.g. vs a box-corer (Hilbing 2004) or vs an Agassiz trawl (Schwabe et al. 2007;). In all these cases, however, no quantitative and statistical comparisons between the sampling gears performances were performed.

At the beginning of our study we were not expecting many new findings from the TAN0802 voyage, at least for the shelf area, given the extensive sampling effort done in the past along the Ross Sea shelf (e.g. Rehm et al. 2007; Ghiglione et al. 2013; Błażewicz-Paszkowycz et al. 2014; Piazza et al. 2014; Schiaparelli et al. 2014) and new records were only expected from deeper strata, only rarely investigated in the past.

However, the TAN0802 data suggest that for molluscs, even in shallow waters, we are still far from a complete knowledge as more new records and new species are continuously added to the general inventory of the Ross Sea molluscs. For the Ross Sea area, Dell (1990) reported a total of 193 species (considering the classes Gastropoda, Bivalvia, Polyplacophora and Scaphopoda). In the last 25 years and, in particular, following the expeditions of the last decade, this number has doubled, increasing up to 392 species (belonging to the same mollusc classes considered in Dell 1990).

The number of new records and new species added to the Ross Sea inventory has been dramatic. It increased by $20 \%$ after the Latitudinal Gradient Program (R/V Italica 2004) and TAN0402 BioRoss voyage (R/V Tangaroa 2004) expeditions (Schiaparelli et al. 2006), followed by further $18 \%$ after the Latitudinal Gradient Program (R/V Italica 2004) expedition (thanks to the use of a Rauschert dredge, Ghiglione et al. 2013; Schiaparelli et al. 2014) and by another $19 \%$ after the TAN0802 (present data). 
The fact that any additional sampling performed is bringing new records even in shelf areas is a conundrum that can be reasonably explained by not only the increase of sampling effort, but also by the fact that part of the recent sampling is based on novel sampling methods, i.e. fine-mesh trawling. When this method is adopted, the proportion of new species that can be found is very high. This is not true only for molluscs as similar results in the Ross Sea were also found for Tanaidacea (Pabis et al. 2015) and Isopoda (Lörz et al. 2013) with $85 \%$ and $72 \%$ of new species respectively.

Of course, species richness is just one aspect of biodiversity, and it might even not be the target of a survey focused on the understanding of specific causal factors and the relationship between environmental features and benthic community structure. In these cases, the use of 'standard' gears, as grabs (Cummings et al. 2010) or box-corers (Barry et al. 2003), is the only feasible solution for evaluating the possible influence of specific features on the distribution of benthic organisms, such as the percentage of fine sand and silt and the ratio of sediment chlorophyll a to phaeophytin (as in Cummings et al. 2010) or the organic percentage in seafloor sediments (as in Barry et al. 2003).

In contrast, towed gears, provide a cross-habitat description, integrating different habitats and communities but, regrettably, do not allow the explanation of species richness and abundances based on specific environmental variables. However, when taxonomic richness is the targeted variable and the study has the aim to evaluate diversity over large spatial scales, fine-mesh towed gears ensure the best efficiency in catching highest numbers of species and specimens. In polar areas, where sampling constraints may be really high, such sampling methods could accelerate our knowledge increase of diversity and hence build the basis of future, more detailed sampling activities, to be performed by using purely quantitative methods, such as grabs or box-corers.

Our results suggest that sampling with fine-mesh towed gears if routinely included in future benthic sampling activities in Antarctica, could greatly extend our knowledge of biodiversity, especially in areas where limited sampling has been performed in the past.

\section{Acknowledgements}

We would like to acknowledge the crew of the Tangaroa 'IPY-CAML TAN0802' for logistic support. We are indebted to the New Zealand Ministry of Fisheries (MFish) and NIWA (Wellington) for the financial support of the cruise and related study activities. We are indebted to Laura D'Annibale for sorting operations at the Italian National Antarctic Museum (Section of Genoa).

This paper is a contribution to the multinational Latitudinal Gradient Project and contribution \#XXXX to the Census of Antarctic Marine Life (CAML). We thank the Italian PNRA for the financial 
support to the research program BAMBi (Barcoding of Antarctic Marine Biodiversity, PNRA 2010/A1.10).

\section{References}

Ainley DG (2002) The Ross Sea, Antarctica, where all ecosystem processes still remain for study, but maybe not for long. Mar Ornithol 30:55-62

Ainley DG (2010) A history of the exploitation of the Ross Sea, Antarctica. Polar Rec 46:233-243

Albano PG, Sabelli B, Bouchet P (2011) The challenge of small and rare species in marine biodiversity surveys: microgastropod diversity in a complex tropical coastal environment. Biodivers Conserv 20:3223-3237

Bardou P, Mariette J, Escudié F, Djemiel C, Klopp C (2014) jvenn: an interactive Venn diagram viewer. BMC Bioinformatics 15:1. doi:10.1186/1471-2105-15-293

Barry JP, Grebmeier JM, Smith J, Dunbar RB (2003) Oceanographic Versus Seafloor-Habitat Control of Benthic Megafaunal Communities in the SW Ross Sea, Antarctica. In: G. R. Ditullio and R. B. Dunbar (eds) Biogeochemistry of the Ross Sea, American Geophysical Union, Washington, pp 327-353. doi:10.1029/078ARS21

Błażewicz-Paszkowycz M, Siciński J (2014) Diversity and distribution of Tanaidacea (Crustacea) along the Victoria Land Transect (Ross Sea, Southern Ocean). Polar Biol 37:519-529. doi:10.1007/s00300-014-1452-7

Bouchet P, Lozouet P, Maestrati P, Heros V (2002) Assessing the magnitude of species richness in tropical marine environments: exceptionally high numbers of molluscs at a New Caledonia site. Biol J Linn Soc Lond 75:421-436. doi:10.1046/j.1095-8312.2002.00052.x

Bowden DA, Schiaparelli S, Clark MR, Rickard GJ (2011) A lost world? Archaic crinoid-dominated assemblages on an Antarctic seamount. Deep Sea Res Part 2 Top Stud Oceanogr 58:119-127. doi:10.1016/j.dsr2.2010.09.006

Bracegirdle T, Stephenson D (2012) Higher precision estimates of regional polar warming by ensemble regression of climate model projections. Climate Dynamics 1-17. doi:10.1007/s00382-012-1330-3,

Brandt A (1995) Peracarid fauna (Crustacea, Malacostraca) of the Northeast Water Polynya off Greenland: documenting close benthic-pelagic coupling in the Westwind Trough. Oceanograph Lit Rev 121:3951 doi:10.3354/meps121039

Brandt A, De Broyer C, Gooday AJ, Hilbig B, Thomson MR (2004) Introduction to ANDEEP (ANtarctic benthic DEEP-sea biodiversity: colonization history and recent community patterns) a tribute to Howard L. Sanders. Deep Sea Res Part 2 Top Stud Oceanogr 51:1457-1465. doi:10.1016/j.dsr2.2004.08.006

Brandt A et al. (2013) Epifauna of the Sea of Japan collected via a new epibenthic sledge equipped with camera and environmental sensor systems. Deep Sea Res Part 2 Top Stud Oceanogr 86:43-55. doi:10.1016/j.dsr2.2012.07.039

Brandt A, Elsner NO, Malyutina MV, Brenke N, Golovan OA, Lavrenteva AV, Riehl T (2015) Abyssal macrofauna of the Kuril-Kamchatka Trench area (Northwest Pacific) collected by means of a camera-epibenthic sledge. Deep Sea Res Part 2 Top Stud Oceanogr 111:175-187. 
doi:10.1016/j.dsr2.2014.11.002

Brandt A et al. (2014) Composition and abundance of epibenthic-sledge catches in the South Polar Front of the Atlantic. Deep Sea Res Part 2 Top Stud Oceanogr 108:69-75. doi:10.1016/j.dsr2.2014.08.017

Brenke N (2005) An epibenthic sledge for operations on marine soft bottom and bedrock. Mar Technol Soc J 39:10-21. doi:http://dx.doi.org/10.4031/002533205787444015

Chao A, Ma KH, Hsieh TC (2016) iNEXT (iNterpolation and EXTrapolation) Online. Program and User's Guide published at http://chao.stat.nthu.edu.tw/wordpress/software download/

Chao A, Gotelli NJ, Hsieh TC, Sander EL, Ma K, Colwell RK, Ellison AM (2014) Rarefaction and extrapolation with Hill numbers: a framework for sampling and estimation in species diversity studies. Ecol Monograph 84:45-67. doi:10.1890/13-0133.1

Chao A, Jost L (2012) Coverage-based rarefaction and extrapolation: standardizing samples by completeness rather than size. Ecology 93:2533-2547. doi:10.1890/11-1952.1

Chao A, Colwell RK, Lin C-W, Gotelli NJ (2009) Sufficient sampling for asymptotic minimum species richness estimators. Ecology 90:1125-1133. doi:10.1890/07-2147.1

Clark MR, Stewart R (2016). "The NIWA seamount sled: An effective epibenthic sledge for sampling epifauna on seamount and rough seafloor." Deep-Sea Research Part I Oceanographic Research Papers. 108:32-38.

Clark MR, Schlacher T, Menezes G, Molodsova T (2015). Survey and sampling design. Biological Sampling in the Deep Sea. In: MR Clark, M Consalvey, AA Rowden (Eds) Biological Sampling in the Deep Sea. John Wiley \& Sons. Ltd. pp 36-56.

Clarke A, Griffiths HJ, Linse K, Barnes DK, Crame JA (2007) How well do we know the Antarctic marine fauna? A preliminary study of macroecological and biogeographical patterns in Southern Ocean gastropod and bivalve molluscs. Divers Distrib 13:620-632. doi:10.1111/j.1472-4642.2007.00380.x

Clarke A, Johnston NM (2003) Antarctic marine benthic diversity. Oceanogr Mar Biol 41:47-114

Clarke KR (1993) Non parametric multivariate analyses of changes in community structure. AUST J ECOL 18:117-143. doi:10.1111/j.1442-9993.1993.tb00438.x

Clarke KR, Gorley RN (2005) PRIMER: Getting started with v6 PRIMER-E Ltd, Plymouth

Colwell RK, Chao A, Gotelli NJ, Lin S-Y, Mao CX, Chazdon RL, Longino JT (2012) Models and estimators linking individual-based and sample-based rarefaction, extrapolation and comparison of assemblages. J Plant Ecol 5:3-21. doi:10.1093/jpe/rtr044

Cummings V, Thrush S, Chiantore M, Hewitt J, Cattaneo-Vietti R (2010) Macrobenthic communities of the north-western Ross Sea shelf: links to depth, sediment characteristics and latitude. Antarct Sci 22:793-804. doi:http://dx.doi.org/10.1017/S0954102010000489

Dell RK (1990) Antarctic Mollusca. With special reference to the fauna of the Ross Sea. J R Soc N Z Bull 27:1-311

Eléaume M, Hemery LG, Bowden DA, Roux M (2011) A large new species of the genus Ptilocrinus (Echinodermata, Crinoidea, Hyocrinidae) from Antarctic seamounts. Polar Biol 34:1385-1397. doi:10.1007/s00300-011-0993-2

Gaston KJ, Williams PH (1993) Mapping the world's species-the higher taxon approach. Biodiversity Letters: 2-8. doi:10.2307/2999642

Ghiglione C, Alvaro MC, Griffiths H, Linse K, Schiaparelli S (2013) Ross Sea Mollusca from the 
latitudinal gradient program: R/V Italica 2004 Rauschert dredge samples. ZooKeys 341:37-48. doi:10.3897/zookeys.341.6031

Ghiglione C, Carota C, Nava CR, Soldani I, Schiaparelli S (2015) Rarefaction and extrapolation with Hill numbers: a study of diversity in the Ross Sea. In: Proceedings of the GRASPA2015 Conference, Bari. pp 15-16

Griffiths HJ, Danis B, Clarke A (2011) Quantifying Antarctic marine biodiversity: The SCAR-MarBIN data portal. Deep Sea Res Part 2 Top Stud Oceanogr 58:18-29. doi:10.1016/j.dsr2.2010.10.008

Griffiths HJ, Linse K, Crame JA (2003) SOMBASE-Southern Ocean Mollusc Database: a tool for biogeographic analysis in diversity and ecology. Org. Divers. Evol. 3:207-213. doi:10.1078/1439-6092-00079

Hanchet S, Mitchell J, Bowden D, Clark M, Hall J, O'Driscoll R (2008) Ocean survey 20/20 NZ IPYCAML: final voyage report. NIWA Client Report WLG2008-74

Hessler R, Sanders ML (1967) Faunal diversity in the deep sea. In: Deep Sea Res and Oceanographic Abstracts 14:65-78. doi:10.1016/0011-7471(67)90029-0

Hilbig B (2004) Polychaetes of the deep Weddell and Scotia Seas - composition and zoogeographical links. Deep Sea Res Part II 51:1817-1825.

Hsieh T, Ma K, Chao A (2013) iNEXT online: interpolation and extrapolation (Version 1.0)[Software] Available from http://chao stat nthu edu tw/blog/software-download

IPCC (2013) Climate Change: The Physical Science Basis. Contribution of Working Group I to the Fifth Assessment Report of the Intergovernmental Panel on Climate Change. Cambridge University Press, Cambridge, United Kingdom and New York, USA

Jörger K, Schrödl M, Schwabe E, Würzberg L (2014) A glimpse into the deep of the Antarctic Polar Front-Diversity and abundance of abyssal molluscs. Deep Sea Res Part 2 Top Stud Oceanogr 108:93-100. doi:10.1016/j.dsr2.2014.08.003

Kaiser S, Barnes DKA, Sands CJ, Brandt A (2009) Biodiversity of an unknown Antarctic Sea: assessing isopod richness and abundance in the first benthic survey of the Amundsen continental shelf. Mar Biodiv 39:27-43

Kaiser S, Barnes DKA, Linse K, Brandt A (2008) Epibenthic macrofauna associated with the shelf and slope of a young and isolated Southern Ocean Island. Antarc Sci 20(3):281-290

Kennicutt $M$ et al (2015) A roadmap for Antarctic and Southern Ocean science for the next two decades and beyond. Antarc Sci 27:3-18. doi:10.1017/S0954102014000674

Linse K (2004) Scotia Arc deep-water bivalves: composition, distribution and relationship to the Antarctic shelf fauna. Deep Sea Res Part 2 51:1827-1837

Linse K and Brandt A (1998) Distribution of Epibenthic Molluscs on a Transect Through the Beagle Channel (Southern Chile). Journal of the Marine Biological Association of the UK 78(03):875889

Longino JT, Coddington J, Colwell RK (2002) The ant fauna of a tropical rain forest: estimating species richness three different ways. Ecology 83:689-702. doi:10.1890/00129658(2002)083[0689:TAFOAT]2.0.CO;2

Lörz A-N, Kaiser S, Bowden D (2013) Macrofaunal crustaceans in the benthic boundary layer from the shelf break to abyssal depths in the Ross Sea (Antarctica). Polar Biol 36:445-451. doi:10.1007/s00300-012-1269-1

McClain CR (2004) Connecting species richness, abundance and body size in deep-sea gastropods. 
Glob. Ecol. Biogeogr., 13:327-334. doi:10.1111/j.1466-822X.2004.00106.x

Mitchell J, Clark M (2004) Voyage Report Tan04-02. Western Ross Sea Voyage:1-102

Pabis K, Jóźwiak P, Lörz A-N, Schnabel K, Błażewicz-Paszkowycz M (2015) First insights into the deep-sea tanaidacean fauna of the Ross Sea: species richness and composition across the shelf break, slope and abyss. Polar Biol 38:1429-1437. doi:10.1007/s00300-015-1706-z

Piazza P, Błażewicz-Paszkowycz M, Ghiglione C, Alvaro MC, Schnabel K, Schiaparelli S (2014) Distributional records of Ross Sea (Antarctica) Tanaidacea from museum samples stored in the collections of the Italian National Antarctic Museum (MNA) and the New Zealand National Institute of Water and Atmospheric Research (NIWA). ZooKeys 451:49-60. doi:10.3897/zookeys.451.8373

Piazza P, Alvaro MC, Bowden DA, Clark MR, Conci N, Ghiglione C, Schiaparelli S (2015) First record of living Acesta (Mollusca: Bivalvia) from an Antarctic seamount. Mar Biodivers 46:529-530. doi:10.1007/s12526-015-0397-6.

Rehm P, Thatje S, Mühlenhardt-Siegel U, Brandt A (2007) Composition and distribution of the peracarid crustacean fauna along a latitudinal transect off Victoria Land (Ross Sea, Antarctica) with special emphasis on the Cumacea. Polar Biol 30:871-881. doi:10.1007/s00300-006-0247$\mathrm{x}$

Scambos T, Haran T, Fahnestock M, Painter T, Bohlander J (2007) MODIS-based Mosaic of Antarctica (MOA) data sets: Continent-wide surface morphology and snow grain size. Remote Sens Environ 111:242-257. doi:10.1016/j.rse.2006.12.020

Schiaparelli S, Danis B, Wadley V, Stoddart DM (2013) The Census of Antarctic Marine Life: the first available baseline for Antarctic marine biodiversity. In: C. Verde, G. di Prisco (Eds) Adaptation and Evolution in Marine Environments, Volume 2. Springer Berlin Heidelberg, pp 3-19

Schiaparelli S, Ghiglione C, Alvaro MC, Griffiths HJ, Linse K (2014) Diversity, abundance and composition in macrofaunal molluscs from the Ross Sea (Antarctica): results of fine-mesh sampling along a latitudinal gradient. Polar Biol 37:859-877. doi:10.1007/s00300-014-1487-9

Schiaparelli S, Lörz A-N, Cattaneo-Vietti R (2006) Diversity and distribution of mollusc assemblages on the Victoria Land coast and the Balleny Islands, Ross Sea, Antarctica. Antarct Sci 18:615631. doi:http://dx.doi.org/10.1017/S0954102006000654

Schwabe E, Bohn JM, Engl W, Linse K, Schrödl M (2007) Rich and rare - First insights into species diversity and abundance of Antarctic abyssal Gastropoda (Mollusca). Deep Sea Res Part 2 Top Stud Oceanogr 54:1831-1847. doi:10.1016/j.dsr2.2007.07.010

Souza JLP, Baccaro FB, Landeiro VL, Franklin E, Magnusson WE, Pequeno PACL, Fernandes IO (2016) Taxonomic sufficiency and indicator taxa reduce sampling costs and increase monitoring effectiveness for ants. Diversity and Distributions 22:111-122 
Figure legend:

Figure 1. Map of sampling stations performed during the TAN0802 IPY-CAML voyage in the Ross Sea, Antarctica. Stations' coordinates are reported in Supplementary Table 1.

Figure 2. Richness rarefaction and extrapolation analyses performed with iNEXT on abundance data (Brenke sled stations only) among the considered latitudinal areas.

Figure 3. MDS plot of all gears combined (presence/absence data) considering the factor "Latitudinal area".

Figure 4. Venn diagram showing the number of species collected during the TAN0802 by each gear and the number of shared species.

Figure 5. Number of species occurring in each size class. Size classes are according to Bouchet et al. (2002) and have equivalent intervals in a $\log _{2}$ transformation.

Figure 6. Richness rarefaction and extrapolation analyses performed with iNEXT on presence/absence data. Abbreviations: $\mathrm{ORH}=$ Rough-bottom trawl; $\mathrm{SEH}=$ Brenke sled; $\mathrm{SEL}=$ Epibenthic sled; TB = Beam trawl. (a). Rarefaction and extrapolation output for the factor gear. (b). Sample coverage output from the factor gear.

Supplementary Figure 1. Maps of gear deployments during the TAN0802 voyage.

Supplementary Figure 2. Numbers of species and specimens collected by each gear divided per mollusc class. Abbreviations: BIV = Bivalvia; GAS = Gastropoda; $\mathrm{MON}=$ Monoplacophora; $\mathrm{POL}=$ Polyplacophora; SCA = Scaphopoda; SOL = Solenogastres on incidence data (Brenke sled data only) for the bathymetric classes considered. 


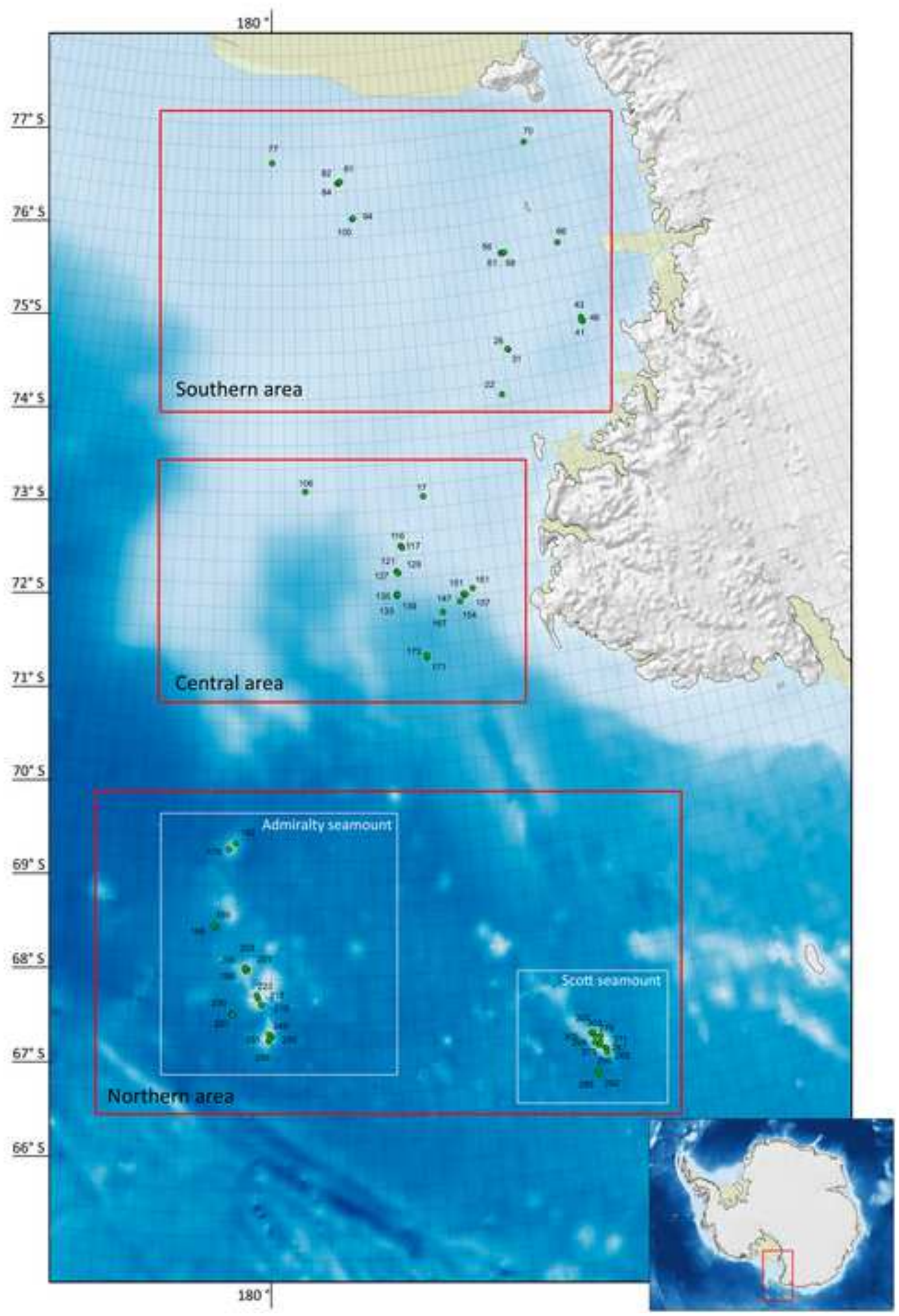




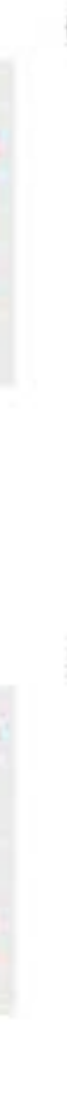

(a)

(c)

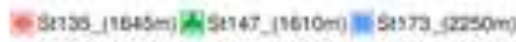

(e)

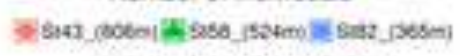

- nacpolasos. edrapolason
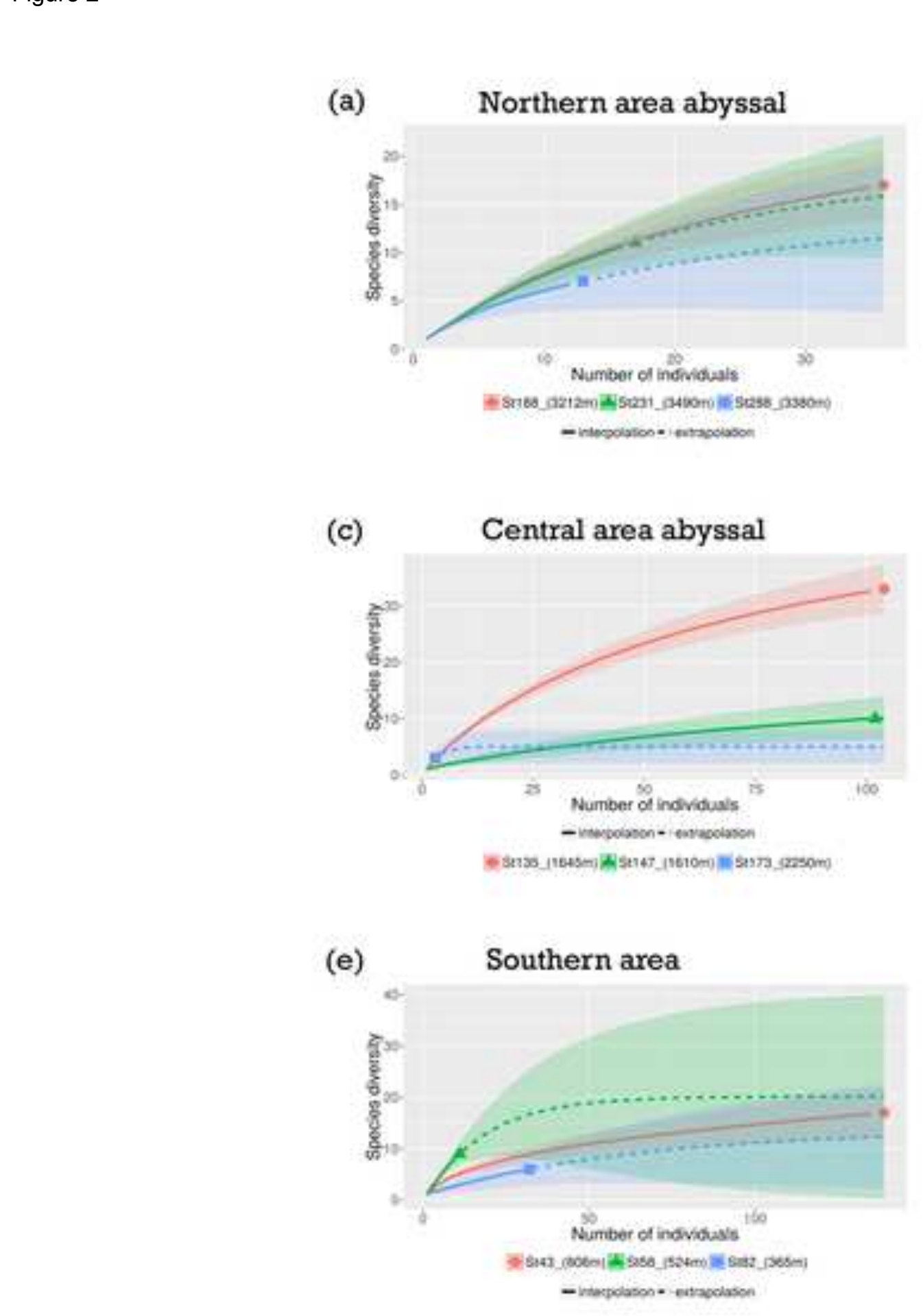

(b)

\section{Northern area shallow}

(d)
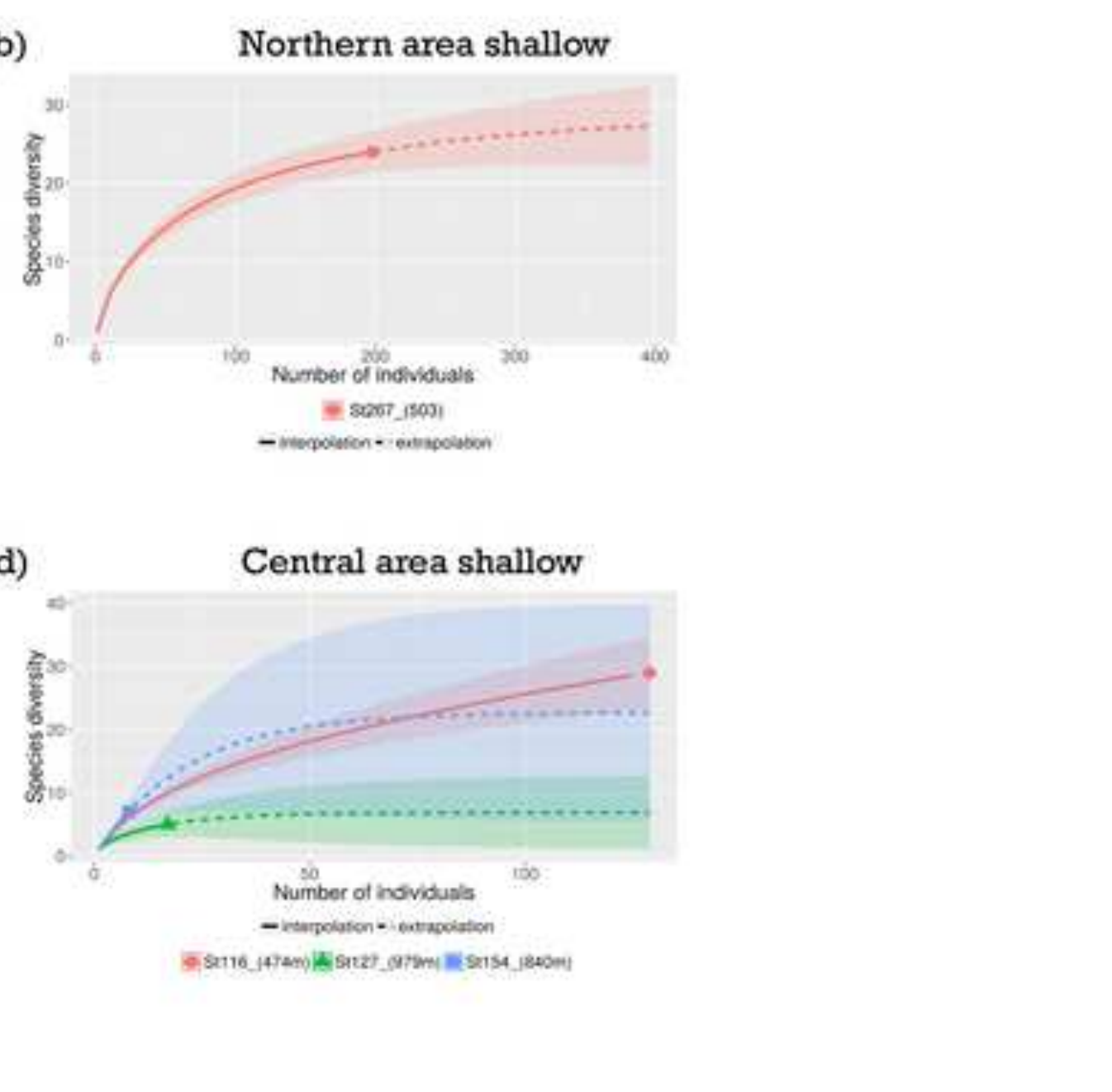
Transform: Presencelabsence

Resemblance: S17 Bray Curtis similarity

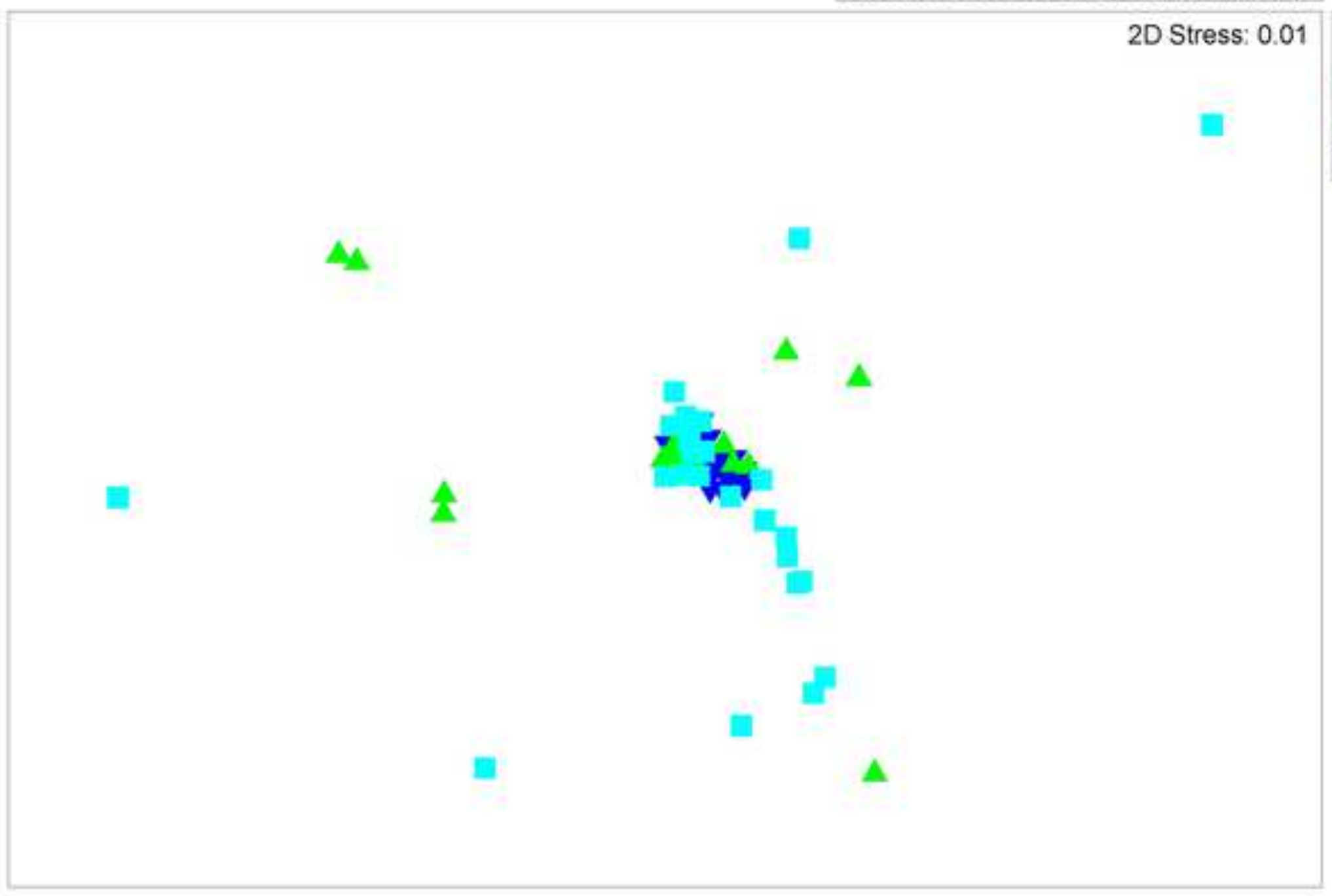

Latitudinal Area

- Northern Area

$\triangle$ Central Area

$\nabla$ Southern Area 

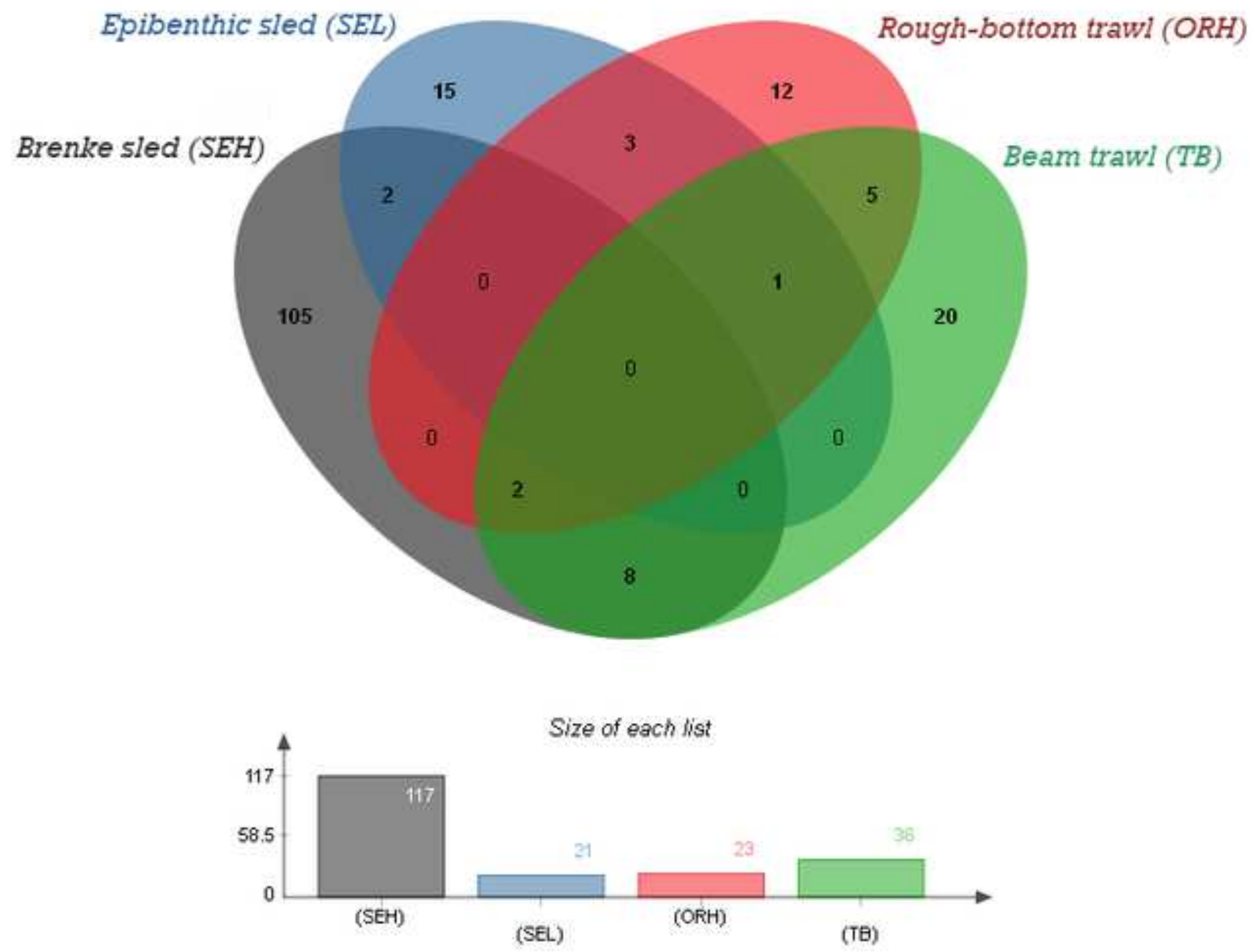


\section{Number of species occurring at each size class (in $\mathrm{mm}$ )}

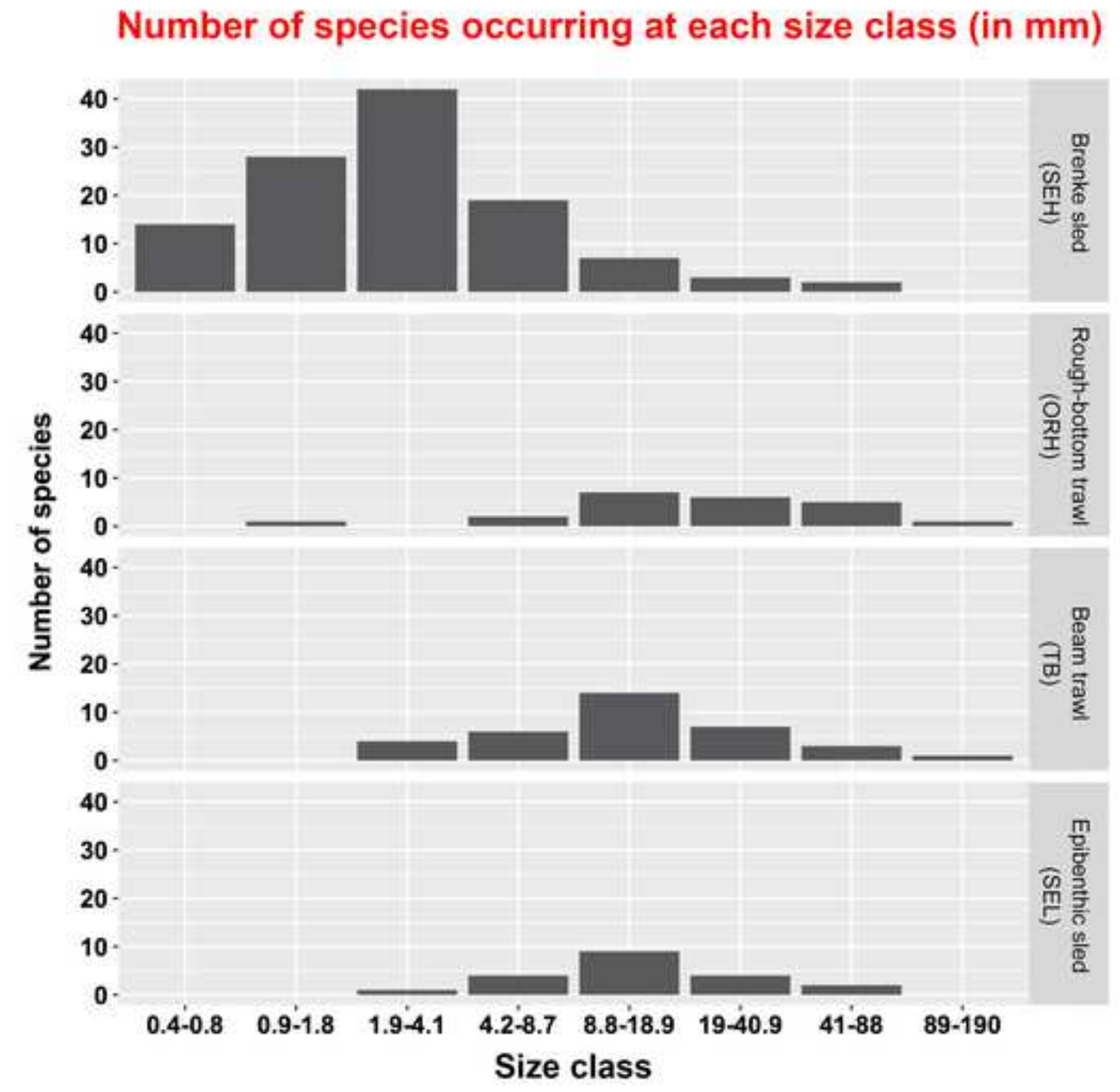


(a)

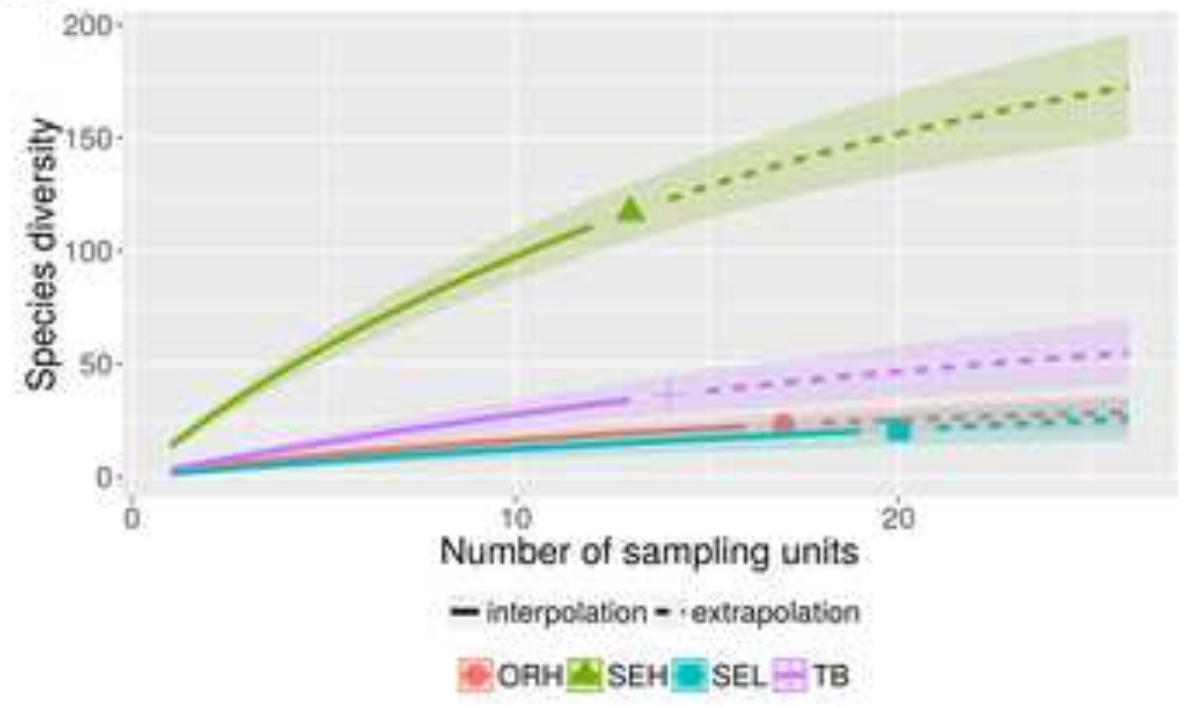

(b)

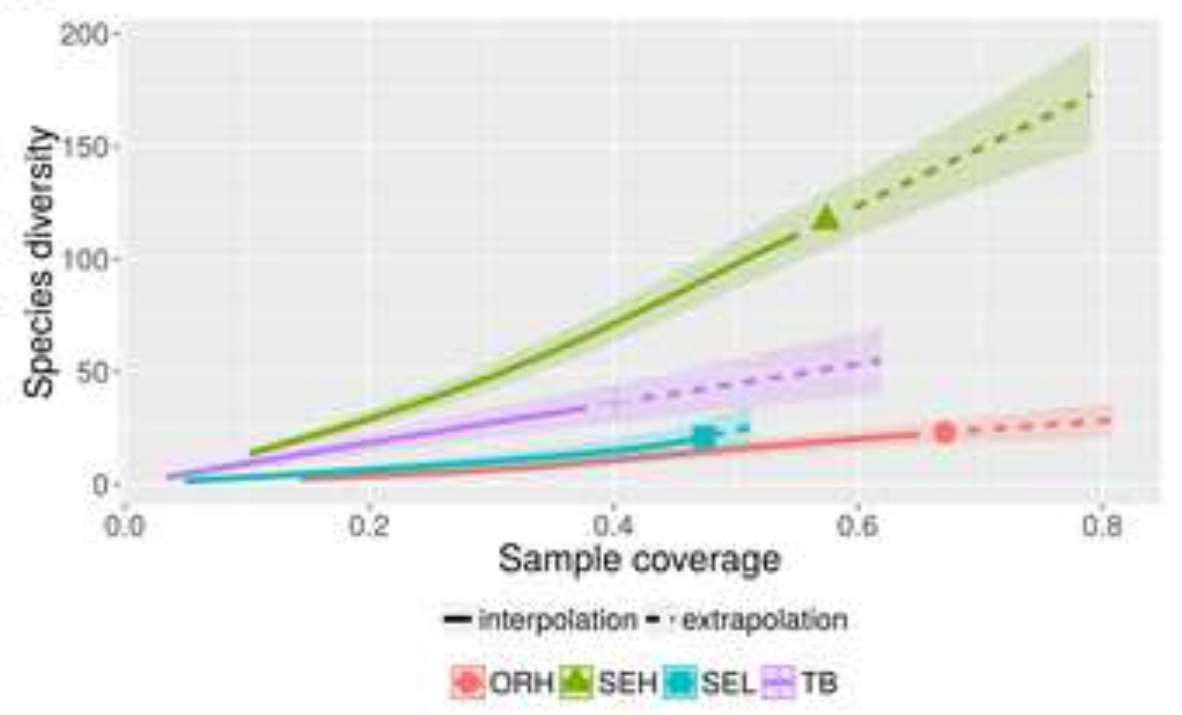




\begin{tabular}{lccc}
\hline $\begin{array}{l}\text { Table 1. Sampling performance with different deployed gears showing new records } \\
\text { and new species. }\end{array}$ & New records & New species & Nº $^{\circ}$ specimens \\
\hline Gear & 15 & 8 & 202 \\
\hline Brenke sled (SEH) & 4 & 2 & 7 \\
Beam trawl (TB) & 2 & 1 & 16 \\
Epibenthic sled (SEL) & 0 & 1 & 3 \\
Rough-bottom trawl (ORH) & \multicolumn{4}{c}{} \\
\hline Total & &
\end{tabular}




\begin{tabular}{|c|c|c|c|c|}
\hline & $\mathrm{R}$ & Sign. (\%) & Actual permutations & Observed \\
\hline $\begin{array}{l}\text { Global R } \\
\text { Pairwise test }\end{array}$ & 0.111 & 0.1 & & \\
\hline Central Area vs Southern Area & 0.089 & 10 & 999 & 99 \\
\hline Central Area vs Northern Area & 0.074 & 0.3 & 999 & 2 \\
\hline Southern Area vs Northern Area & 0.169 & 0.1 & 999 & 0 \\
\hline
\end{tabular}




\begin{tabular}{|c|c|c|c|c|}
\hline & $\mathrm{R}$ & Sign. (\%) & Actual permutations & Observed \\
\hline $\begin{array}{l}\text { Global R } \\
\text { Pairwise test }\end{array}$ & 0.021 & 19.7 & & \\
\hline $0-500 \mathrm{~m}$ vs $501-1000 \mathrm{~m}$ & -0.011 & 59.9 & 999 & 598 \\
\hline $0-500 m$ vs $>1001 \mathrm{~m}$ & 0.059 & 9.9 & 999 & 98 \\
\hline $501-1000 m$ vs $>1001 \mathrm{~m}$ & 0.037 & 12.4 & 999 & 123 \\
\hline
\end{tabular}




\begin{tabular}{lcccc}
\hline \multicolumn{6}{l}{$\begin{array}{l}\text { Table 4. One-way ANOSIM analysis for factor gear considering all gears combined (presence/absence } \\
\text { data). }\end{array}$} & $\mathrm{R}$ & Sign. (\%) & Actual permutations & Observed \\
\hline & 0.17 & 0.1 & & \\
\hline Global R & & & 999 & 14 \\
Pairwise test & 0.088 & 1.5 & 999 & 0 \\
ORH - Beam trawl & 0.377 & 0.1 & 999 & 0 \\
ORH - Brenke sled & 0.138 & 0.1 & 999 & 0 \\
ORH - Epibenthic sled & 0.222 & 0.1 & 999 & 0 \\
Beam trawl - Brenke sled & 0.075 & 0.1 & 999 & 0 \\
Beam trawl - Epibenthic sled & 0.195 & 0.1 & & \\
Brenke sled - Epibenthic sled & 0.1 & &
\end{tabular}

